\title{
Análise dos Ciclos de Revisões Tarifáricas Periódicas Em Pernambuco
}

\author{
Analysis Of The Cycles Of Periodic Tariff Reviews In Pernambuco
}

Marcilio Lucas Rocha de Aguiar ${ }^{\mathbf{1}}$ (D) orcid.org/0000-0002-5395-7231

Manoel Henrique Marinho',2 (D) orcid.org/0000-0003-3129-0453

${ }^{1}$ Escola Politécnica de Pernambuco, Universidade de Pernambuco, Recife, Brasil,

E-mail do autor principal: Marcilio Lucas Rocha de Aguiar marciliolra@gmail.com

\section{Resumo}

A análise da Revisão Tarifária Periódica (RTP) é indispensável para a constatação da eficácia dos mecanismos de regulação das tarifas de energia elétrica. Modelos regulatórios quando executados de forma satisfatória trazem a sociedade a vantagem de tarifas a custos módicos sem o comprometimento dos índices de qualidade da energia. Mesmo possuindo propósitos e incumbências definidas, as RTP's sofreram múltiplos aprimoramentos entre seus ciclos, como adoção de novos métodos de Regulação e também a adesão de parâmetros nos cálculos empregados. Este aperfeiçoamento só foi possível devido a experiência absorvida pela reguladora e o grande banco de dados originado do vasto número de concessionárias que vivenciaram estas Revisões. Comenta-se então a RTP e seus objetivos, além das quatro revisões já realizadas pela Companhia Energética de Pernambuco (CELPE). Devido a ampla capacidade técnica procedente de seu extenso capital, as distribuidoras tornam-se beneficiadas no debate sobre regulação tarifária, particularmente nas audiências públicas que precedem este processo.

Palavras-Chave: Revisão Tarifária Periódica, Regulação Tarifária, Fator X, Perdas de Energia, Reposicionamento Tarifário;

\begin{abstract}
The analysis of the Periodic Tariff Review (RTP) is indispensable to verify the effectiveness of the regulation mechanisms of electric energy tariffs. Regulatory models when performed satis-factorily bring society the advantage of low cost tariffs without compromising energy quality indices. Even with defined purposes and tasks, the RTPs underwent multiple enhancements between their cycles, such as adoption of new methods of regulation and also adherence of parameters in the precalculations. This improvement was only possible due to the experience absorbed by the regulator and the large database originating from the vast number of conces-sionaires who experienced these reviews. RTP and its objectives are discussed, in addition to the four revisions already made by Companhia Energética de Pernambuco (CELPE). Due to their extensive technical capacity from their extensive capital, the distributors benefit from the debate on tariff regulation, particularly in the public hearings that precede RTP.
\end{abstract}

Key-words: Periodic Tariff Review, Tariff Adjustment, X Factor, Energy Loss, Tariff Repositioning. 


\section{Introdução e Objetivos}

As reformas que vem sendo introduzidas no setor elétrico ao longo do tempo têm como objetivo buscar um modelo que consiga preservar os diversos interesses de seus consumidores, que garanta aos investidores uma rentabilidade condizente com a atividade praticada e estimule uma constante busca pela eficiência neste setor. Como relatado em [1] esta busca pelo modelo ideal se faz necessária uma vez que mesmo com os avanços obtidos nas últimas décadas, os setores de transmissão e distribuição de energia elétrica continuarão funcionando com a estrutura de mercado de monopólio natural.

Também é visto em [2] que nesta específica estrutura de mercado, a tarifa tem um papel de suma importância que é de reprimir os abusos de poder de monopólio exemplificado através da tomada de preço por parte do produtor, assim como evitar assimetria de informações a favor dos produtores e impor práticas que resultem em uma maior eficiência produtiva, alocativa.

De modo geral, a tarifa de energia elétrica deve ser uma forma de controle e ajuste dos preços que serão cobrados pela distribuição, bem como o grau de liberdade que estes preços podem variar de acordo com a classe do consumidor, garantindo uma rentabilidade atrativa ao investidor e induzindo o produtor a estar sempre buscando uma eficiência que o permita inovar e reduzir custos e preços no futuro aliado a uma melhor qualidade do produto como relatado em [3].

Em [4] é visto que o método de regulação mais utilizado na tarifação da energia elétrica é o do custo de serviço, utilizado historicamente no Brasil, principalmente a partir de 1980 . O pricecap, iniciado pela Light em 1996 após sua desestatização, e a tarifação pelo custo marginal, são outros métodos de regulação tarifária pou-co utilizados nas distribuidoras brasileiras e internacionais ao longo das últimas décadas. Para auxiliar cada modelo de regulação, foram desenvolvidos mecanismos complementares, que tem como meta atenuar as desvantagens verificadas por cada modelo, como o intervalo de revisão das tarifas, o Yardstick Competition e as licitações.

A tarifa de energia elétrica ao consumidor final no Brasil é regulada pela Agência Nacional de Energia Elétrica - ANEEL. Como relatado em [5] é um dos serviços públicos com maior cobertura da população brasileira além de possuir grande importância para diversos ramos da economia.

Uma das formas de regulação da tarifa se dá pela Revisão Tarifária Periódica (RTP), e no caso da Companhia Energética de Pernambuco (CELPE), acontece desde 2005 e seu ciclo dura quatro anos.

De acordo com [6] o objetivo da RTP é redefinir o nível das tarifas, com o intuito de conservar o equilíbrio econômico-financeiro da concessão, e ainda repassar aos consumidores possíveis aumentos de eficiência advindos do período entre revisões.

Devido a sua importância, descrevem-se as etapas e a forma de como a RTP é realizada, além de uma comparação histórica dos quatro ciclos de revisão transitados pela Celpe, elencando alguns resultados destes processos, como a trajetória de índices de Perda de Energia, de Qualidade dos serviços prestados pela concessionária, e os possíveis ganhos de eficiência repassados aos consumidores. Ainda é feito uma comparação desses resultados com de algumas outras concessionárias do país.

\section{Justificativa}

Conforme se relata em [7] o modo de fixação das tarifas varia conforme mercados de diferentes países. Nos mercados onde há regulamentação, este processo é monitorado pelos reguladores conforme os modelos de regulação adotados.

Em [8] pode ser visto que a regulação de tarifas em monopólios naturais tem o objetivo de simular a concorrência e que a dificuldade para a fixação de tarifas neste caso, é que os reguladores nunca saberão exatamente como se dá o funcionamento do negócio tanto quanto os proprietários, fato este chamado de "assimetria da informação".

Em [9] pode-se verificar que os riscos devem ser colocados sobre estas empresas visto que elas se beneficiam de possuir certa vantagem de informação. Por este motivo, é necessário propiciar altas taxas de rendibilidade para compensação do elevado risco do negócio.

O monopólio do sistema de distribuição de energia elétrica traz consigo diversos desafios. Estabelecer o preço da tarifa torna-se uma tarefa delicada, devido à falta de um sistema de preços livres e a necessidade de determinar um valor que possibilite as concessionarias prestarem serviços com bons índices de qualidade, além de remunerar seus investimentos e cobrir o risco do negócio. Isso tudo, preservando o preço da tarifa de forma a resguardar 
os consumidores do impacto econômico que elevadas tarifas de energia elétrica causariam.

\section{Métodos de Regulação em outros países}

Como relatado ainda em [9] não é possível identificar um "melhor" conjunto de mecanismos regulatórios dadas as peculiaridades de cada país. Abaixo se podem verificar os modelos de regulação tarifária de alguns países:

Em [10] relata-se que os modelos adotados no Chile são o "Yardstick Competition" e o "Price Cap". A RTP acontece de modo sistemático a cada 4 anos para as distribuidoras do país.

É relatado em [10] que o método "Yardstick Competition" ocorre quando a performance da concessionária é comparada com outras de porte e características semelhantes. Este mecanismo tenta propiciar a competição indireta entre distribuidoras que operam em áreas diferentes.

O método "Price Cap" visto em [11] é um método de regulação por incentivos que se baseia na fixação de um preço teto, onde a cada ano, o valor da tarifa é recalculado tomando como base o valor do ano anterior, ajustado por um índice inflacionário menos um fator de eficiência $X$.

Ainda em [10] verifica-se que no Reino Unido se utilizou o modelo "Price Cap" durante mais de duas décadas e que para os próximos períodos serão adotados a regulação "RIIO" (Revenue = incentives + innovation + outputs). Esta será caracterizada pelos altos investimentos em tecnologias ainda a serem desenvolvidas e um considerável grau de incerteza.

$\mathrm{Na}$ china, é mencionado em [10] que os mecanismos de regulação não são utilizados de forma recorrente e transparente, não existindo separação dos custos de distribuição e transmissão. Neste país, a regulação ocorre nos ajustes da geração e do varejo a partir dos preços praticados.

Por fim ainda em [10] relata-se que na Noruega, adota-se o modelo "Revenue Cap" onde as receitas das empresas são calculadas pelos custos destas e um "benchmarking". Também é dado um grande incentivo para as empresas buscarem a segurança do abastecimento.

Em [12] ver-se que o modelo "Revenue Cap" é considerado um caso particular da regulação "Price Cap" por ser bastante semelhante a esta.

\section{Métodos de Regulação no Brasil}

Como visto em [13] após a implementação da Lei no 8.987/1995, abandonou-se a regulação de controle sobre o lucro e o controle de preços foi adotado como formato de regulação das distribuidoras de energia no país. A dificuldade para determinação das tarifas neste tipo de regulação está em definir o valor dos custos das empre-sas que teriam quer ser repassada aos consumidores.

Um modelo de "Benchmark Regulation" foi logo utilizado para levantamento desses custos. Como verificado em [14], neste mecanismo uma empresa fictícia, chamada de Empresa de Referência, é criada para levantamento dos custos ideais e imposta a concessionaria.

Para concepção desta Empresa, exige-se uma estrutura bastante robusta da reguladora a fim de desenvolver estudos técnicos que idealizem os parâmetros de uma empresa ideal.

Como relatado em [15], as assimetrias de informação marcaram o método de forma negativa, pois as estimativas dos custos divergiram dos custos reais das empresas. Também é relatado que estas empresas se beneficiaram de uma regulação menos rigorosa nas primeiras revisões.

A partir do terceiro ciclo das revisões, a reguladora passou a adotar o método "Yardstick Competition". Assim, a ANEEL caracterizou as concessionárias em função da complexidade dos sistemas e áreas atendidas por estas para efeito de comparação de resultados. Com isso, índices de qualidade dos serviços prestados pela distribuidora e de perdas de energia, de cada concessionária, seriam comparados entre elas, e ou ainda, o melhor índice já obtido pela própria concessionária, podiam se tornar a trajetória regulada a ser alcançada.

\section{Estrutura Tarifária e Revisão Tarifária Periódica}

Com a celebração dos contratos de concessão das empresas de distribuição de energia elétrica no país, a regulação da tarifa ficou evidenciada em três circunstâncias possíveis; o Reajuste Tarifário Anual (RTA), a Revisão Tarifária Extraordinária (RTE) e a Revisão Tarifária Periódica (RTP). Para melhor entendimento de como ocorre esta regulação, é importante primeiramente elucidar que a tarifa de energia elétrica é estruturada em duas parcelas principais; parcela A e parcela $\mathrm{B}$.

http: / / dx.doi.org/10.25286/repa.v4i1.587 
Pode-se ver em [5] que a Parcela A contempla os custos não gerenciáveis da empresa, ou seja, valores ao qual a empresa não tem controle como o custo de transmissão, compra de energia e impostos, as quais são repassadas de forma integral aos consumidores.

Já em [16] é descrito que a Parcela B contempla os custos gerenciáveis da distribuidora como custos operacionais e despesas de capital. Esta é corrigida no processo de Reajuste Tarifário Anual (RTA), de acordo com o índice inflacionário, ajustado por outro índice que procura induzir as distribuidoras à busca da eficiência operacional, conhecido como Fator X. Na Fig.1 pode-se observar o percentual dos itens que constituem as Parcelas A e B, na qual apenas o Custo de Distribuição - 20,7\%, corresponde a parcela B.

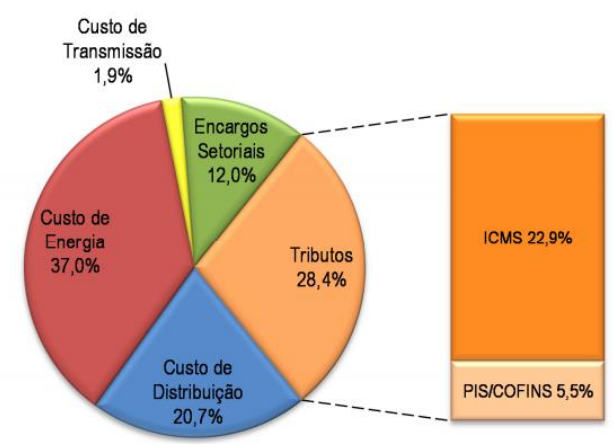

Figura 1. Gráfico [22]: mostra a participação dos itens das Parcelas A e B e dos tributos para a receita da CELPE em 2016.

Em [17] é relatado que na RTP são redefinidos o nível eficiente dos custos operacionais e a remuneração dos investimentos, sendo realizado em duas etapas. $\mathrm{Na}$ primeira, chamada de Reposicionamento Tarifário, há a preocupação de estabelecer tarifas que possibilitem cobrir os custos operacionais eficientes e os investimentos. $\mathrm{Na}$ segunda etapa é realizado o cálculo do Fator $X$, onde se estabelece metas de eficiência que serão expressas nas tarifas dos anos subsequentes dentro do ciclo.

Pode se ver em [18] que quando as empresas diminuem seus custos abaixo do estipulado pela reguladora na RTP, podem se apropriar dessa diferença durante o ciclo tarifário aumentando seus lucros. Ao final do ciclo tarifário, em nova RTP, os ganhos com essa eficiência são repassados aos consumidores.

\subsection{Resultados do Reposicionamento Tarifários (RT) da CELPE}

Em [19] relata-se que o cálculo do RT se expressa na comparação de uma receita requerida suficiente para remunerar as despesas de operação e manutenção, os investimentos prudentes e o capital aplicado, com uma receita verificada (ou projetada) no período de um ano, como visto na equação abaixo:

$$
R T=\left(\frac{R R-O R}{R V}-1\right) \cdot 100
$$

Em que,

RT: Reposicionamento Tarifário Médio (\%);

RR: Receita Requerida - Soma das Parcelas A e B;

OR: Outras Receitas - Receitas de atividades empresariais extra concessão ou ainda de prestação de serviços cobráveis ou taxados, arrendamento, alugueis, entre outros;

RV: Receita Verificada.

$\mathrm{Na}$ primeira RTP, como dito anteriormente, a ANEEL adotou o "Benchmark Regulation" como método de regulação da RR pela concessionaria.

Homologado em [20], o resultado final da Revisão Tarifária Periódica de 2005 estabeleceu um RT definitivo no valor de $23,57 \%$, sendo $12,5 \%$ de aplicação imediata e a diferença convertida em acréscimos de parcelas, nos respectivos reajustes tarifários anuais de 2006 a 2008.

De forma equivalente à primeira RTP, a segunda RTP passou pela etapa de RT. Ainda foram considerados outros componentes tarifários financeiros externos como subsídios de irrigação e subsídios de baixa renda entre outros, para o cálculo final. Estes componentes externos de $14,47 \%$, se sobrepuseram ao reposicionamento tarifário negativo de $6,61 \%$ da RTP, como visto na Tabela 1 .da referida normativa, resultando no aumento final de $8,31 \% \mathrm{em}$ face da possível diminuição da tarifa de energia antes esperada.

\begin{tabular}{ccc}
\hline \multicolumn{1}{c}{ DESCRIÇÃO } & $\begin{array}{c}\text { VALOR } \\
\text { [R\$] }\end{array}$ & [\% ] \\
\hline Receita Requerida Líquida & $\mathrm{R} \$ 2.424 .303 .946,98$ & \\
\hline Receita Verificada & $\mathrm{R} \$ 2.583 .410 .606,91$ & \\
\hline ÍNDICE DE REPOSICIONAMENTO TARIFÁRIO & $\mathbf{- 6 , 1 6 \%}$ \\
\hline FINANCEIROS EXTERNOS AO REPOSICIONAMENTO & $\mathbf{1 4 , 4 7 \%}$ \\
\hline $\begin{array}{c}\text { ÍNDICE DE REPOSICIONAMENTO TARIFÁRIO } \\
\text { (considerando o efeito dos financeiros) }\end{array}$ & $\mathbf{8 , 3 1 \%}$ \\
\hline
\end{tabular}

Tabela 1: Valores em [21] mostra o resumo do RT de 2009. 
A partir do terceiro ciclo, houve a adoção do modelo "Yardstick Competition", onde a reguladora instaurou o PRORET (Procedimento de Regulação Tarifária), documentos divididos em sub módulos, com o intuito de criar novas metodologias de cálculo tarifário para todas as distribuidoras de energia.

É válido destacar que houve vários ajustes nos cálculos para atualização dos custos do $2^{\circ}$ RTP devido à mudança de abordagem dos custos operacionais e de seus vários componentes. As metodologias aplicáveis a $3^{\circ}$ RTP, passaram a ser definidas nos Módulos 2 e 7 do PRORET, que tratam respectivamente, do cálculo da revisão tarifária e da estrutura tarifária aplicável.

Como relatado em [22], depois de atualizados os valores de custos operacionais da Empresa de Referência (ER), foi realizada uma comparação de eficiência das distribuidoras conforme suas áreas de atuação e o nível dos seus custos para determinação dos novos custos operacionais.

Sendo assim, o RT calculado foi de 1,61\%, conforme (1). Analogamente a $2^{\mathrm{a}}$ RTP, o RT mencionado em [22] também considerou outros componentes financeiros externos que alteraram o RT final, causando um efeito médio de $2,65 \%$ aos consumidores.

Na quarta RTP, o RT foi feito de forma bastante correlata à $3^{a}$ RTP e é relatada em [23] utilizando-se de (1). Conforme o referido documento, o valor calculado para o período foi de $8,19 \%$ sem considerar os Componentes Financeiros Externos.

\subsection{Fator $X$}

Na segunda etapa do processo da RTP, realiza-se o cálculo do Fator X. Como mencionado em [19], neste tipo de regulação, a empresa é fortemente incentivada em sua gestão a conquistar altos índices de eficiência. Logo, ao ter menos custos operacionais que os determinados pela RTP, ela reterá esta diferença aumentando a margem de lucro do negócio até a RTP seguinte, como visto na Parcela B da Figura 2, nas áreas verde e amarela. Pode-se ainda perceber que a Parcela A é totalmente repassada ao custo da tarifa. Na RTP posterior, este ganho de produtividade e eficiência é repassada aos consumidores.

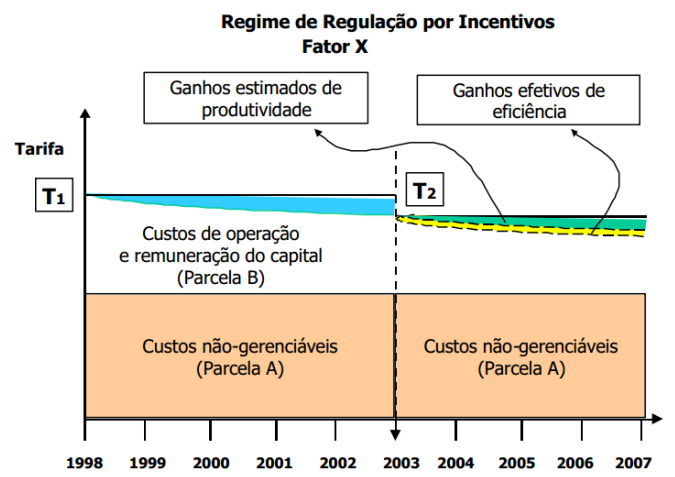

Figura 2: Gráfico de [19] mostra a representação do Regime de Regulação por Incentivos

Na primeira RTP este procedimento foi realizado conforme preconizava [20], que estabelecia o Fator $X$ em função dos componentes abaixo;

I - componente Xe que refletia os ganhos de produtividade esperados derivados da mudança na escala do negócio por incremento do consumo de energia elétrica na área servida, tanto por maior consumo dos consumidores existentes, como pela incorporação de novos consumidores, no período entre revisões tarifárias;

II - componente Xc que refletia a avaliação dos consumidores sobre a sua concessionária, sendo obtido mediante a utilização do resultado da pesquisa Índice ANEEL de Satisfação do Consumidor - IASC; e

III - componente Xa que refletia a aplicação do Índice de Preço ao Consumidor Amplo (IPCA) para o componente mão-de-obra da Parcela B da concessionária.

A componente $X e$ foi calculada na RTP vigente e os componentes Xc e Xa foram calculados no momento do reajuste anual, com dados dos referidos anos. Para esta RTP, o valor de Xe teve como resultado $0,6142 \%$.

Abaixo segue o modelo de cálculo para os reajustes tarifários anuais, o qual está inserido o fator $\mathrm{X}$ :

$I R T=\frac{V P A 1+V P B 0 \cdot(|V|+X)}{R A 0}$

Em que,

IRT = Índice de Reajuste Tarifário;

VPA1 - Valor da Parcela A;

VPBO - Valor da Parcela B;

RAO - Receita Anual;

$|\mathrm{V}|$ - Número índice obtido pela divisão dos http: / / dx.doi.org/10.25286/repa.v4i1.587 
índices do IGPM da Fundação Getúlio Vargas;

$X$ - Fator $X$.

Na segunda RTP, o Fator $X$ fora computado de forma equivalente à primeira RTP em função de $X a$, $X c$ e Xe. Agora com base na metodologia estabelecida pelo documento [21], o cálculo do componente $\mathrm{Xe}$, único elemento calculado durante esta RTP, resultou no valor de 0,37\%.

Para a terceira RTP, a reguladora em [22] modificou a metodologia de cálculo do Fator $X$ no terceiro ciclo das revisões conforme fórmula abaixo:

$$
\text { Fator } X=P d+Q+T
$$

Em que os componentes $P d$ e $T$ são determinados no instante da RTP e o componente $\mathrm{Q}$ em cada reajuste tarifário anual, ainda que sua metodologia fosse desde já conhecida nos documentos do PRORET.

I - Pd: - Este componente consistia nos ganhos de produtividade das distribuidoras pela variação de mercado e das unidades consumidoras. Neste ciclo foi calculado em 1,22\%.

II- T: A metodologia para cálculo de $T$ essencialmente trata da transição entre metodologias para a definição de custos operacionais eficientes devido a mudança do método regulatório. Nesta RTP foi calculada em $0,46 \%$

III - Q: Este componente tem por finalidade incentivar a melhoria da qualidade do serviço prestado pelas distribuidoras, alterando as tarifas de acordo com o comportamento dos Indicador DEC, o qual relaciona a duração equivalente de interrupção por unidade consumidora, expressa em horas e do Indicador FEC, que indica a frequência equivalente de interrupção por unidade consumidora, expressa em número de interrupções.

Na quarta Revisão relacionada em [23] foram considerados os mesmos componentes da Revisão anterior para a definição do Fator X. Entretanto, estes também sofreram atualizações na metodologia de cálculo. Em resumo, os resultados verificados foram os seguintes; a Componente $\boldsymbol{P d}$ foi calculada em 1,33\% e o componente $\boldsymbol{T}$ em $0 \%$.

Já a componente $\mathrm{Q}$ incorporou indicadores comerciais como a FER (Frequência Equivalente de Reclamação) e ICO (Índice de Chamadas Ocupadas do Atendimento Telefônico).

As Figuras 3 e 4 mostram os indicadores de continuidade coletivos DEC e FEC relacionados aos seus valores limites desde a concessão da CELPE até o fim do $3^{\circ}$ ciclo de regulação tarifária:

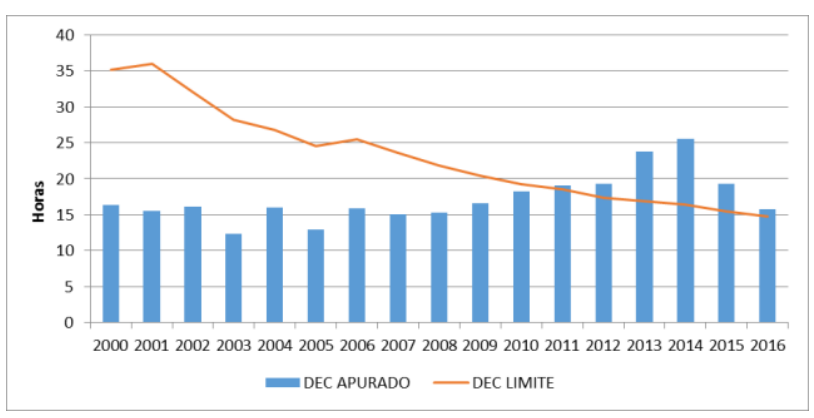

Figura 3: Gráfico elaborado pelo autor a partir de dados encontrados em site da ANEEL demostrando a evolução do indicador DEC e do limite estipulado pela reguladora como referência.

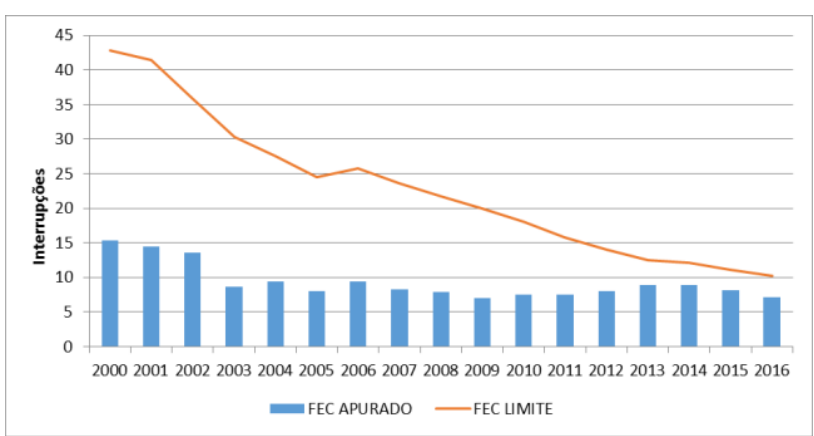

Figura 4: Gráfico elaborado pelo autor a partir de dados encontrados em no site da ANEEL demostrando a evolução do indicador FEC e do limite estipulado pela reguladora como referência.

Os limites estabelecidos pela reguladora neste caso serviram apenas como parâmetros a serem atingidos pelas concessionárias. Porém há outros limites estabelecidos em [22] para os índices de continuidade individuais que quando transgredidos resultam em compensações financeiras aos consumidores como evidenciado na Figura 5:

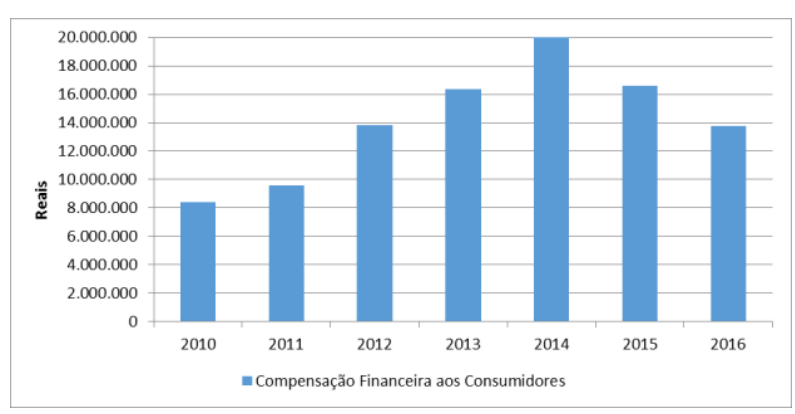

Figura 5: Gráfico elaborado pelo autor a partir de dados encontrados no site da ANEEL demostrando a evolução da compensação financeira aos consumidores realizado pela CELPE. 


\subsection{Perdas de Energia}

Outro fator importante que influencia na RR pela concessionária está relacionado às perdas da energia Elétrica que a reguladora permita que a concessionária repasse aos consumidores. Ela está inserida na Parcela A da tarifa e é determinada por uma trajetória regulada anual a partir da RTP. É importante ainda esclarecer que estas perdas podem ser divididas em duas categorias: Perdas Técnicas e Perdas Não Técnicas.

Em [21], relata-se que as Perdas Técnicas são derivadas da energia elétrica dissipada decorrente das leis da Física devido ao transporte da energia, transformação de tensão e medição, entre outros. Já as Perdas Não Técnicas são todas as demais como fraude, furtos de energia, erros de medição dentre outros.

Ainda em [19] menciona-se que as perdas não técnicas se encontravam no momento da primeira RTP em elevados níveis visto que segundo a concessionária, $34,5 \%$ da energia entregue em baixa tensão na região metropolitana do Recife era furtada. Nesta RTP, foi considerada como meta a taxa de $8,32 \%$ em perdas não técnicas sobre a energia injetada na rede para cálculo dos custos da concessionária no fim do ciclo em 2009. A trajetória alcançada neste ciclo pode ser vista abaixo:

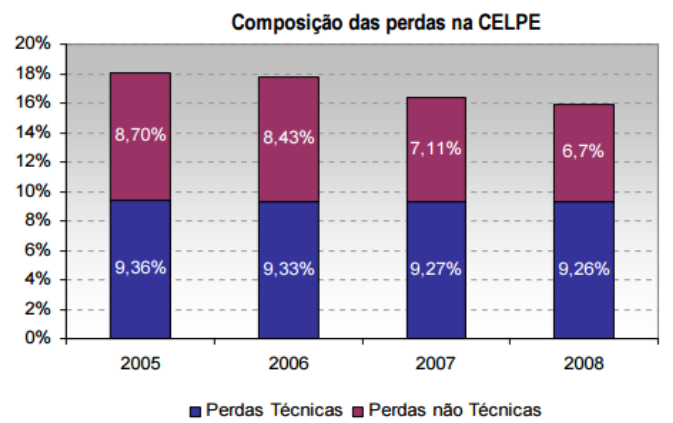

Figura 6: Gráfico de [21] mostra a evolução das perdas durante o ciclo da primeira revisão tarifária em relação a energia injetada na rede.

Na segunda RTP a reguladora estipulou nova trajetória de perdas não técnicas, estipulando o valor de $14 \%$ sobre o mercado de baixa tensão conforme gráfico:

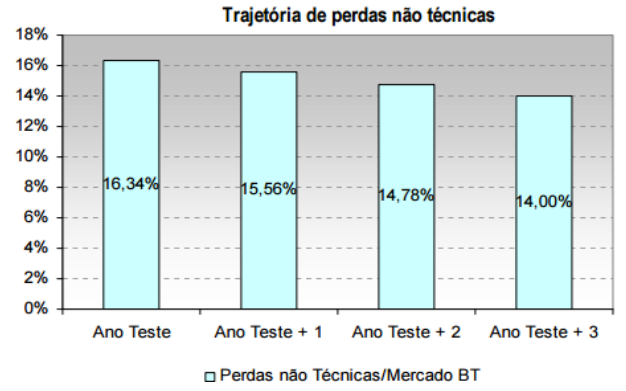

Figura 7: Gráfico de [21] mostra a trajetória regulada das perdas de energia não técnicas sobre o mercado de baixa tensão.

A agência reguladora também estabeleceu como meta no referido documento o valor de $8,34 \%$ para consideração das perdas técnicas no fim do ciclo. É importante destacar que a ANEEL desconsiderou a energia do nível de mercado $A 1$, visto que as perdas desse segmento são mínimas.

Já no terceiro ciclo, a ANEEL passou a comparar o desempenho de distribuidoras conforme áreas de atuação semelhantes. Ainda em [22] menciona-se que o desempenho passado da própria distribuidora também poderia servir de referencial para esta regulação. Nesta RTP, a reguladora definiu em $14 \%$ a meta a ser alcançada durante todo o período para o mercado de Baixa Tensão que é onde ocorre as maiores perdas, como evidenciado na Tabela 2.

\begin{tabular}{|l|c|c|c|c|c|}
\hline \multicolumn{1}{|c|}{ Descrição } & Ponto Partida & 2013 & 2014 & 2015 & 2016 \\
\hline Referencial Regulatório PNT/BT & $14,00 \%$ & $14,00 \%$ & $14,00 \%$ & $14,00 \%$ & $14,00 \%$ \\
Referencial Regulatório PT/Einj & $8,31 \%$ & $8,31 \%$ & $8,31 \%$ & $8,31 \%$ & $8,31 \%$ \\
\hline
\end{tabular}

Tabela 2: Valores em [22] mostra a trajetória regulada do período.

Por fim, na última RTP realizada, foi anexada nova trajetória regulada para CELPE conforme Tabela 3, onde a reguladora incentiva a Distribuidora a novamente diminuir suas perdas no mercado de Baixa Tensão durante o ciclo:

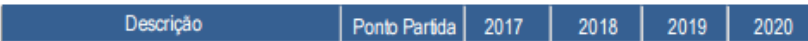

$\begin{array}{llllll}\text { Referencial Regulatorio PNT/BT (faturado) } & 14,000 \% & 13,792 \% & 13,585 \% & 13,377 \% & 13,169 \%\end{array}$

Tabela 4: Valores em [23] mostra as perdas de energia a ser consideradas durante o período.

\section{Comparativo de Resultados da Celpe com Outras Distribuidoras.}

$\mathrm{Na}$ Figura 8 se podem verificar algumas concessionárias que passaram pelas revisões e os resultados dos RT encontrados desconsiderados os

http: / / dx.doi.org/10.25286/repa.v4i1.587 
componentes externos. É valido destacar que como cada contrato de concessão é único, os anos que ocorreram estes processos se deram como regidos em seus respectivos documentos.

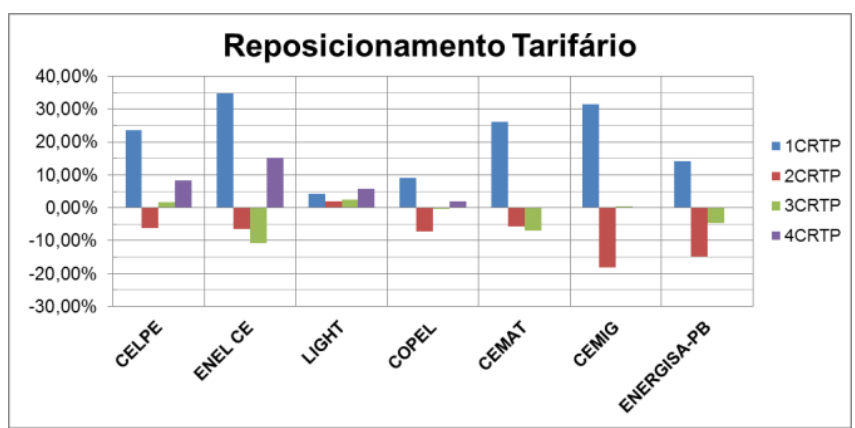

Figura 8: Gráfico elaborado pelo autor a partir de dados dos Atos Regulatórios da ANEEL onde mostra a evolução do Reposicionamento Tarifário de diversas distribuidoras sem consideração dos componentes externos.

Em geral, o primeiro ciclo das revisões retratou um forte RT, que instigou a reguladora a recorrer do princípio da modicidade tarifária para que os aumentos fossem parcelados durante o ciclo. Posteriormente, mesmo havendo RT negativos em alguns ciclos, ainda sim puderam ser vistos aumentos da tarifa de energia devido à consideração de componentes financeiros externos ao RT.

Em relação aos índices de qualidade de energia considerados para cálculo do Fator X, DEC e FEC, nota-se nas Figuras 9 e 10, uma robusta diminuição destes nas empresas que demostravam elevados índices no começo da série histórica.

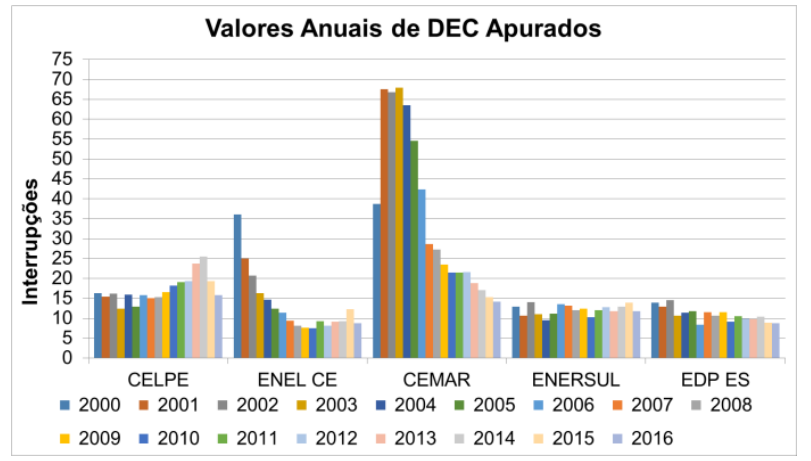

Figura 9: Gráfico elaborado pelo autor a partir de dados encontrado no site da ANEEL para os indicadores coletivos de continuidade.

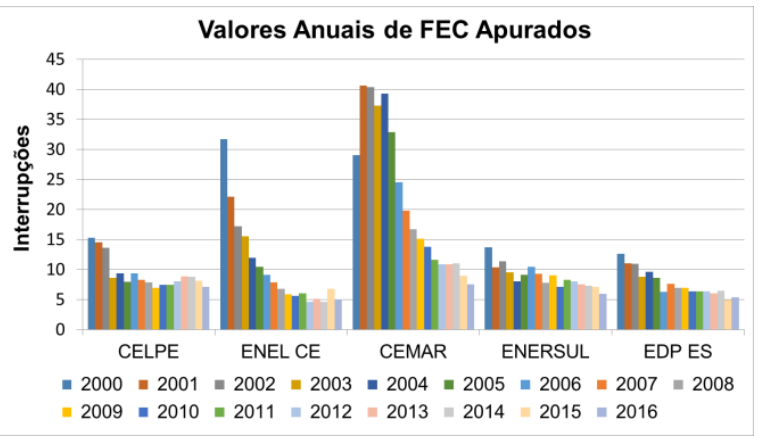

Figura 10: Gráfico elaborado pelo autor a partir de dados encontrados no site da ANEEL para os indicadores coletivos de continuidade.

Para consideração das Perdas de Energia, as primeiras revisões consideravam a energia injetada na rede para definição da trajetória regulada. Uma comparação da média das perdas para o primeiro ciclo pode ser vista na Tabela 4:

\begin{tabular}{|l|r|c|}
\hline \multicolumn{1}{|c|}{ Empresa } & $\begin{array}{c}\text { Perdas NT I } \\
\text { Energia injetada }\end{array}$ & $\begin{array}{c}\text { Perdas NT I } \\
\text { mercado BT }\end{array}$ \\
\hline CELPE & $7,82 \%$ & $17,12 \%$ \\
COELBA & $6,71 \%$ & $15,63 \%$ \\
COSERN & $3,23 \%$ & $7,55 \%$ \\
COELCE & $5,87 \%$ & $12,38 \%$ \\
CEAL & $22,57 \%$ & $65,59 \%$ \\
CEMAR & $16,18 \%$ & $30,63 \%$ \\
CELPA & $17,46 \%$ & $41,38 \%$ \\
ELETROPAULO & $7,69 \%$ & $16,84 \%$ \\
LIGHT & $15,00 \%$ & $42,32 \%$ \\
\hline
\end{tabular}

Tabela 4: Em [21] mostra a média das perdas durante o ciclo da primeira revisão tarifária e a comparação com outras distribuidoras neste período.

A partir dos segundos ciclos, em geral, a reguladora passou a objetivar as perdas sobre 0 mercado de baixa tensão, visto que é neste grupo que se encontra a maior parte dessas perdas. Observa-se na Figura 11 a evolução de algumas concessionárias como a CEMAR, considerada de mesmo porte da CELPE, a ENEL CE, apontada como empresa de referência por possuir os melhores resultados, e outras concessionárias do país.

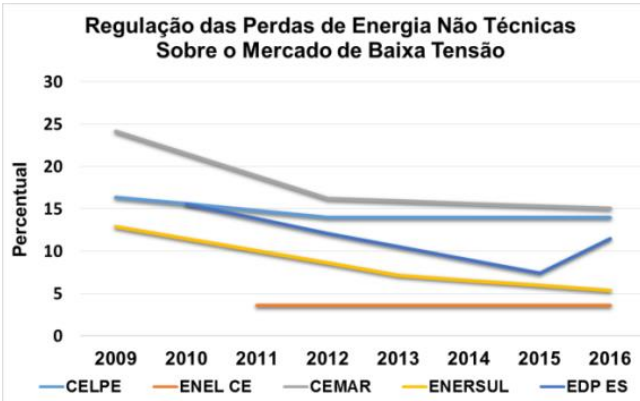

Figura 11: Gráfico elaborado pelo autor a partir de dados dos Atos Regulatórios da ANEEL onde mostra a evolução da regulação das perdas de energia não técnicas 
sobre o mercado de baixa tensão faturado.

Consegue-se perceber que no último ciclo tarifário da EDP ES, houve um aumento do valor a ser considerado para cálculo das perdas desta distribuidora. Isto se deveu pela reclassificação do grau de complexidade da área atendida pela empresa, a qual permitiu uma inflexão na trajetória regulada para a concessionária.

\section{Conclusão}

Analisar a Revisão Tarifária Periódica é de fundamental importância para verificar se os mecanismos regulatórios estão se mostrando eficientes em relação não apenas a outras concessionárias do país, como também de outros países. Modelos regulatórios quando bem aplicados podem trazer a sociedade o benefício de tarifas mais acessíveis, sem que isso reflita numa piora dos índices de qualidade da energia.

Apesar de possuir objetivos e funções definidas, as Revisões Tarifárias Periódicas passaram por diversos aprimoramentos entre seus ciclos, como mudança de método de Regulação e considerações de novos parâmetros nos cálculos utilizados. Isto só foi possível pela própria experiência assimilada pela agência reguladora e o amplo banco de dados gerados da extensa quantidade de concessionárias que passaram por essas Revisões.

De modo geral, após um primeiro momento com forte RT nas distribuidoras de vários estados, incluindo a CELPE, pode-se perceber uma diminuição nos ciclos seguintes, que teoricamente poderiam levar a redução da tarifa de forma objetiva para os consumidores. Entretanto, a existência de algumas variáveis como subsídios a alguns setores da economia e o próprio mercado de energia se sobrepôs a estas reduções.

Outro tópico analisado evidenciou a importância da RTP para busca da eficiência na gestão da concessionária. A diminuição de forma constante das perdas de energia elétrica permitiu um alívio em um vetor que tende a pressionar o aumento da tarifa, dado que o prejuízo causado por essas perdas se distribuem para o resto dos consumidores que sustentam o sistema.

Já o Fator $X$ demostra evolução para um viés indutor da melhoria dos serviços prestados. É possível verificar o incremento de novos índices de qualidade comerciais além dos já utilizados índices técnicos DEC e FEC.
Como as concessionárias possuem uma grande capacidade técnica derivada de seu grande capital, se tornam favorecidas neste debate de regulação tarifária, principalmente nas audiências públicas que antecedem as RTP's. Devido a isto, a maior participação da sociedade neste processo é de grande relevância para que não haja desequilíbrio de forças no debate regulatório.

É importante observar se os mecanismos de regulação utilizados estão obtendo avanços significativos, os quais necessitam proporcionar tarifas a preços mínimos, mas que possibilitem uma evolução continua na melhoria dos serviços prestados pelas concessionárias.

\section{Referências}

[1] Francisco Rigolon e Maurício Piccinini. Mecanismos de regulação tarifária do setor elétrico: A experiência internacional e o caso brasileiro. BNDES, Rio de Janeiro, 1998

[2] PINDYCK, Robert S.; RUBINFELD, Daniel. L. Microeconomia. 7. Ed., São Paulo: Ed Prentice Hall, 2010. 647 p

[3] JARDIM, Priscila Nunes Fraga Maia. Ganhos e perdas com a implementação do atual modelo regulatório do setor elétrico brasileiro. 2013. (Tese de Mestrado) Programa de Pós-graduação em Planejamento Energético, da Universidade Federal do Rio do Janeiro, 2013.

[4] João Francisco de Castro Carção. Tarifas De Energia Elétrica no Brasil. Dissertação, Escola Politécnica da Universidade de São Paulo, 2011.

[5] Departamento Intersindical de Estatística e Estudos Socioeconômicos. As tarifas de energia elétrica no Brasil: sistemática de correção e evolução dos valores. Nota Técnica, n. 58, DIEESE, Dez 2007.

[6] Departamento Intersindical de Estatística e Estudos Socioeconômicos. As tarifas de energia elétrica no Brasil: inventário do $3^{\circ}$ ciclo de revisão tarifária e os efeitos sobre o setor. Nota Técnica, n. 134, DIEESE, Dez 2014.

[7] Economic Development and Labour Bureau Government of the Hong Kong Special Administrative Region. Electricity Market Review: http: / / dx.doi.org/10.25286/repa.v4i1.587 
electricity tariff. Relatório Técnico, Out 2002. http://www.enb.gov.hk/sites/default/files/en/nod e73/Reference03.pdf

[8] John Swinscoe. A Review of Energy Tariffs in INOGATE Partner Countries. Relatório Técnico, Inogate, Jun 2015

[9] Directorate General for Energy. Study on tariff design for distribution systems: final report. Relatório Técnico, European Commission, Jan 2015.

[10] CPFL Energia. Aspectos conceituais da regulação econômica, modelo tarifário e mecanismo de formação das tarifas nos 25 países estudados. Relatório Técnico, Jun 2015.

[11] Ronaldo Fiani. Teoria da Regulação Econômica: Estado Atual e Perspectivas Futuras. [S.I], [s.n], 2004..

[12] Satu Viljainen. Regulation Desing in the Electricity Distribution Sector: Theory and Practice. Tese de Doutorado. Finlândia: Lappeenran-ta University of Technology, 2005.

[13] Érico Henrique Garcia de Brito. Revisão tarifária e diferenças regionais: um estudo de concessões de distribuição de energia elétrica no Brasil. Dissertação, Universidade de São Paulo, 2009

[14] Sobre regulação por comparação e Empresa de Referência, ver Anuatti Neto, Pelin e Peano (2004) e Danni \& Moita (2006).

[15] Hamilton C. D. Silva. Cost Efficiency in Periodic Tariff Reviews: The Reference Utility Approach and the Role of Interest Groups; Public Utility Research Center, 30p, 2011.

[16] Sérgio Kinya Fugimoto. Estrutura de Tarifas de Energia Elétrica Análise Crítica e Proposições Metodológicas. Tese de Doutorado, Escola Politécnica da Universidade de São Paulo, 2010.

[17] Departamento Intersindical de Estatística e Estudos Socioeconômicos. A revisão tarifária da energia elétrica numa perspectiva dos trabalhadores do setor. Nota Técnica, n. 70, DIEESE, Jul 2008.
[18] Maria do Amparo Coutinho. Revisão Tarifária Periódica dos Contratos de Concessão de Serviços de Distribuição de Energia Elétrica: A Questão do Equilíbrio Econômico-Financeiro. Monografia, Instituto Serzedello Corrêa, 2004.

[19] Agência Nacional de Energia Elétrica. Revisão Tarifária Periódica da Concessionária de Distribuição de Energia Elétrica: Companhia Energética de Pernambuco. Nota Técnica, n. 106, SRE/ANEEL, Mar 2005.

[20] Agência Nacional de Energia Elétrica. Resolução Homologatória. Relatório Técnico, $\mathrm{n}$. 316, ANEEL, Abr 2006.

[21] Agência Nacional de Energia Elétrica. Segunda Revisão Tarifária Periódica da Concessionária de Distribuição de Energia Elétrica: CELPE, ciclo 2009 - 2013. Nota Técnica, n. 150, SRE/ANEEL, Abr 2009.

[22] Agência Nacional de Energia Elétrica. Terceira Revisão Tarifária Periódica da Concessionária de Distribuição de Energia Elétrica CELPE, ciclo 2011 - 2014. Nota Técnica, n. 134, SRE/ANEEL, Abr 2013.

[23] Agência Nacional de Energia Elétrica. Quarta Revisão Tarifária Periódica da Concessionária de Distribuição de Energia Elétrica: CELPE, nota Técnica, n. 96 SRE/ANEEL, Abr 2017. 